Jameson, J. E. \& Emberley, N. W. (1958). J. gen. Microbiol. 18, 238

\title{
Teepol in Substitution for Bile Salts
}

\author{
By J. E. JAMESON AND N. W. EMBERLEY
}

Public Health Laboratory, Brighton

SUMMARY: When any grade of Teepol, other than Teepol 530, Teepol L or Teepol (without suffix), is used in culture media, the authors recommend that it should first be tested for suitability.

The use of Teepol, a modern anionic detergent marketed by the Shell Chemical Company Ltd., was described by Jameson \& Emberley (1956) as a substitute for bile salts in culture media.

In July 1957 the authors again wrote to the Shell Chemical Company and asked whether it would be possible for an assurance to be given that no product differing materially in composition from that previously supplied to them would in the future be marketed under the trade name of Teepol. In their reply the manufacturers stated that formulations incorporating various types of surface active agents were marketed under the Teepol brand name and the active ingredients of these were not all identical chemically. Teepol 530 was the brand originally used by Jameson \& Emberley (1956). Teepol L, marketed through British Drug Houses Ltd., is of similar chemical constitution as is also the material marketed in the U.K. for general cleaning purposes under the Teepol brand without suffix. Other brands of Teepol with suffixes different from those enumerated above may be based on different surface active agents or contain additives and should, therefore, be tested for suitability before use in the manner described by Jameson \& Emberley (1956).

\section{REFERENCE}

JAmeson, J. E. \& Emberley, N. W. (1956). A substitute for bile salts in culture media. J. gen. Microbiol. 15, 198.

(Received 19 August 1957) 